\title{
THE IMPACT OF GREETING PERSONALIZATION ON PREVALENCE ESTIMATES IN A SURVEY OF SEXUAL ASSAULT VICTIMIZATION
}

\author{
ASHLEY K. GRIGGS* \\ MARCUS E. BERZOFSKY \\ BONNIE E. SHOOK-SA \\ CHRISTINE H. LINDQUIST \\ KIMBERLY P. ENDERS \\ CHRISTOPHER P. KREBS \\ MICHAEL PLANTY \\ LYNN LANGTON
}

\begin{abstract}
Although personalized invitations tend to increase response rates in web surveys, little is known about how personalization impacts data quality. To evaluate the impact of personalization on survey estimates of sensitive items, the effects of personalized and generic greetings in a survey $(n=9,673)$ on an extremely sensitive topic-sexual assault victimization-were experimentally compared. Personalization was found to have increased response rates with negligible impact on
\end{abstract}

Ashley K. Griggs is a survey methodologist at RTI International, Research Triangle Park, NC, USA. MARcus E. BERZOFSKY is a senior research statistician at RTI International, Research Triangle Park, NC, USA. BonNIE E. SHOOK-SA is a student in the Doctor of Public Health Program and research assistant in the Department of Biostatistics at the University of North Carolina at Chapel Hill, Chapel Hill, NC, USA. Christine H. LINDQUist is a senior research sociologist at RTI International, Research Triangle Park, NC, USA. KIMBERLY P. ENDERS is a student in the Doctor of Public Health program and research assistant in the Department of Biostatistics at the University of North Carolina at Chapel Hill, Chapel Hill, NC, USA. Christopher P. Krebs and Michael Planty are chief scientists at RTI International, Research Triangle Park, NC, USA. LYNN LANGTON is the chief of the Victimization Statistics Unit at the Bureau of Justice Statistics, US Department of Justice, Washington, DC, USA. The authors thank the Bureau of Justice Statistics (BJS) for its valuable contributions to and sponsorship of this research. The views expressed in this manuscript are those of the authors only and do not reflect the views or position of BJS or the Department of Justice. Funding for this research was provided by the Department of Justice, Office of Justice Programs, through cooperative agreement 2011-NV-CX-K068 to C.P.K. *Address correspondence to: Ashley Griggs, RTI International, 3040 East Cornwallis Road, PO Box 12194, Research Triangle Park, NC 27709-2194, USA; email: agriggs@rti.org. 
victimization reporting, and this impact was similar across most demographic groups. The findings suggest that future studies may benefit from the use of a personalized greeting when recruiting sample members to participate in a sensitive survey, but that further research is necessary to better understand how the impact of personalization on reporting may differ across some demographic groups.

\section{Background}

A common technique to increase survey response rates is to tailor messages or contact materials to individual sample members. This personalization can be done in any mode of contact using information known about sample members, such as their demographic characteristics or interests. In general, experimental (e.g., Muñoz-Leiva et al. 2010; Sauermann and Roach 2013) and meta-analysis research (e.g., Cook, Heath, and Thompson 2000; Edwards et al. 2009) suggest that personalization increases web-survey response rates (see Pearson and Levine [2003]; Porter and Whitcomb [2003]; Joinson, Woodley, and Reips [2007] for exceptions).

For instance, a meta-analysis conducted by Edwards et al. (2009) indicates that the odds of response increase by about 25 percent with personalized contact materials. Consistently, numerous studies have found that name personalization in invitation emails increases response rates in web surveys of college students (e.g., Heerwegh et al. 2005; Heerwegh 2005; Heerwegh and Loosveldt 2006; Joinson and Reips 2007). However, little is known about how personalization impacts responses to questions on sensitive topics.

Sensitive topics tend to (1) be intrusive and inappropriate in everyday conversation; (2) elicit responses that may be considered socially unacceptable; and (3) raise concerns among respondents about the consequences of answering truthfully, due to the potential threat of disclosure (Tourangeau, Rips, and Rasinski 2000). Self-reports on sensitive topics—such as sexual behavior or socially undesirable behaviors such as intoxication — are often biased toward underreporting, particularly if respondents feel uncomfortable discussing them with others (Bradburn et al. 1978).

Consequently, questions on sensitive topics can lead to unit nonresponse (refusing to participate in the survey at all) or item nonresponse (answering only certain questions). Even if sample members $d o$ respond, response quality suffers as topics become more sensitive, due to underreporting of socially undesirable behaviors and overreporting of desirable behaviors (Tourangeau and Yan 2007).

Response quality may suffer even further when sensitive topics are paired with personalization, if respondents worry about their identity and responses being linked. These confidentiality concerns were evident in Heerwegh's (2005) web survey of Belgian college students about attitudes toward marriage/ 
divorce, which included items about sexual attitudes/behavior. Respondents who received a personalized greeting, "Dear [First Name] [Last Name]," in their email invitation were significantly less likely to feel comfortable responding to the questions honestly and sincerely, compared to students who received a generic greeting, "Dear Student." Furthermore, of the 13 respondents who mentioned confidentiality concerns in an open-ended debriefing question, all but one had received the personalized greeting, suggesting unintended consequences of personalization.

Aside from Heerwegh's (2005) findings, there does not appear to be additional research on the impact of personalization on respondents' perceptions of privacy or the impact of those perceptions on their survey responses, particularly on sensitive topics. Heerwegh and Loosveldt (2006) concluded that additional research is necessary to investigate personalization's impact on responses to sensitive questions, such as sexual behavior. This is especially true today, as a decade has passed since much of the personalization research was done (e.g., Heerwegh and Loosveldt 2006), concerns about online privacy likely have changed as the internet has evolved, and reactions to personalized greetings also may have evolved. Furthermore, the impact of personalization on reporting sensitive information likely varies across surveys-depending on survey characteristics like topic, confidentiality assurances, sample, and incentives-so further research is beneficial.

Consequently, a personalization experiment was conducted in a web survey of US college students about sexual assault victimization. Tourangeau, Rips, and Rasinski (2000) suggest that sexual behavior is an intimate-and possibly the most intimate-topic. However, sexual assault victimization is probably even more so, because of the difficulty of the experience and the negative emotions victims often experience, such as shame, guilt, regret, and blame.

Rather than focusing on response rates, this study investigates the effects on self-reported victimization, hypothesizing that compared with the generic greeting, the personalized greeting results in lower rates of self-reported sexual assault victimization. The study also explores, as a secondary research question, how the greeting impacts victimization rates across varied student characteristics. The impact of personalization on victimization reporting was anticipated to differ across demographic groups, especially for members of minority groups who may perceive a greater threat of disclosure.

\section{Methods}

The College Experiences Survey (CES), sponsored by the Bureau of Justice Statistics and conducted by RTI International, invited undergraduate students at nine universities across the United States to participate in a web survey. The aim of the CES was to measure sexual assault victimization and campus climate. Fielded from March through May 2015, the CES included a greeting 
experiment at five of the nine participating schools. For the experiment, sample members were randomly assigned to receive one of two greetings in their survey invitation and reminder emails: personalized ("Dear [First Name]") or generic ("Dear [School Name] Student").

Four of the five schools in the greeting experiment were included for the analyses presented in this paper. One school was excluded because, as the only two-year school in the experiment, it would have skewed the results of the analysis due to different student populations for key characteristics such as age and year of study. ${ }^{1}$ The four schools included in the analysis were fouryear schools in different regions of the United States with undergraduate populations of 2,500 to 10,000 students. Both public and private not-for-profit schools were included.

\section{SAMPLE AND EXPERIMENTAL DESIGN}

Participating schools provided a roster of all undergraduate students at least 18 years old; these rosters were used as the sampling frame. The sample was a simple random sample, stratified by sex. Females $(11,012)$ and males $(8,808)$ were sampled across the four schools, for a total sample size of 19,820. Of these, 6,283 females and 3,390 males participated in the survey, for an unweighted response rate of 48.8 percent (AAPOR RR3; AAPOR 2015). Random assignment to experimental conditions was done separately for each sex to ensure that the proportion of males to females was equal across conditions.

\section{COMMUNICATIONS WITH SAMPLE MEMBERS}

Undergraduate students at the participating schools were notified about the survey in an email from their university president. The email encouraged students to participate in the upcoming survey, which it described as being "about the sexual experiences and attitudes of undergraduate students." The email emphasized that the survey would be completely confidential, any answers provided would not be linked to the respondent's identity, and that RTI, a nonprofit research organization, would conduct the survey. This email used the same greeting, "Dear [School Name] Students," for all students, regardless of their experimental condition.

Survey invitations were emailed to students approximately one week later. This email used the personalized or generic greeting to which each sample member was assigned. The message indicated that the survey was about sexual experiences and attitudes and that responses would be kept confidential. The email also mentioned the survey length (approximately 15 minutes) and incentive (\$25 gift card after completing the survey). Throughout data collection, nonrespondents were sent up to five email reminders; each used the sample member's assigned greeting.

1. Two-year schools do not have third- or fourth-year students, and the average age of first- and second-year students at these schools tends to be older compared to traditional four-year schools. 


\section{ANALYSIS}

When calculating victimization rates, "victimization" was defined as unwanted sexual contact that occurred during the current academic year. The survey defined victimization for respondents as "sexual contact that you did not consent to and that you did not want to happen." The survey included greater detail about this definition and examples of different types of sexual contact (Krebs et al. 2016).

To verify the assumption that the personalized greeting would yield higher response rates, response rates were computed by greeting type and the student characteristics on the sample frame: ${ }^{2}$ sex, year of study, race/ethnicity, location of residence, transfer status, full- or part-time status, grade point average (GPA), and SAT/ACT score. Table 1 presents the response rates and shows that, as expected, the personalized greeting yielded a higher response rate across nearly all student characteristics; the difference was statistically significant for about half of the characteristics.

To test the hypothesis, that relative to generic greetings, personalized greetings would result in lower rates of self-reported victimization, bivariate and multivariate analyses were conducted. For the bivariate analysis, victimization rates were compared by greeting type and student characteristics, which were self-reported ${ }^{3}$ and included gender identity, race/ethnicity, year of study, age, and sexual orientation. Two logistic models were fit for the multivariate analysis. The first logistic model was a main-effects model, with reported victimization status as the dependent variable and the student characteristics and greeting type as the independent variables. ${ }^{4}$ This model tested whether the type of greeting impacted reporting of victimization after controlling for student characteristics. The second logistic model added to the first model interactions between greeting type and student characteristics. This model tested whether the greeting type impacted how a particular type of student reported victimization status, controlling for other student characteristics. Models were run using SUDAAN Version 11 and accounted for the complex survey design and clustered nature of the data. The models were unweighted because the hypotheses were based on students' responses rather than generalizations regarding sexual assault. To assess the fit of the models, a HosmerLemeshow test of the goodness-of-fit was used. The $p$-values for both models

2. The frame data were used over self-reported data, because only frame data were available on nonrespondents.

3. Self-reported characteristics were used over frame characteristics, because the former included data on more characteristics and those self-reported characteristics were of greater interest for the analysis. Furthermore, some of the self-reported variables (e.g., gender identity) were assumed to provide a more accurate representation of students than the corresponding frame variables (e.g., sex).

4. Age was not included in the logistic model because of its high collinearity with year of study. 
Table 1. Response rates by greeting and student characteristics

\begin{tabular}{|c|c|c|}
\hline & \multicolumn{2}{|c|}{ Response rate $(\%)$} \\
\hline & Generic greeting & Personalized greeting \\
\hline All students & 47.1 & $50.6 * *$ \\
\hline \multicolumn{3}{|l|}{ School } \\
\hline A & 39.2 & 40.1 \\
\hline $\mathrm{B}$ & 63.2 & $68.9 * *$ \\
\hline $\mathrm{C}$ & 57.1 & $62.5^{* *}$ \\
\hline $\mathrm{D}$ & 42.1 & $45.8 * *$ \\
\hline \multicolumn{3}{|l|}{ Sex } \\
\hline Male & 36.7 & $40.4 * *$ \\
\hline Female & 55.4 & $58.7 * *$ \\
\hline \multicolumn{3}{|l|}{ Year of study ${ }^{\mathrm{a}}$} \\
\hline First & 53.9 & 57.1 \\
\hline Second & 48.3 & $53.0 * *$ \\
\hline Third & 48.4 & 48.6 \\
\hline Fourth or more & 49.0 & $54.1 * *$ \\
\hline \multicolumn{3}{|l|}{ Age } \\
\hline 18 & 56.0 & 57.6 \\
\hline 19 & 50.9 & $55.1 * *$ \\
\hline 20 & 48.6 & 50.8 \\
\hline 21 & 44.9 & $49.2^{*}$ \\
\hline 22 or older & 40.8 & $44.7 * *$ \\
\hline \multicolumn{3}{|l|}{ Part-time/full-time status } \\
\hline Part-time & 29.7 & 33.2 \\
\hline Full-time & 48.7 & $52.3 * *$ \\
\hline \multicolumn{3}{|l|}{ Race/Ethnicity ${ }^{a}$} \\
\hline White, non-Hispanic & 51.4 & $54.9 * *$ \\
\hline Black, non-Hispanic & 45.6 & 44.7 \\
\hline Hispanic & 54.0 & 51.7 \\
\hline Asian & 44.3 & 48.0 \\
\hline Other $^{\mathrm{b}}$ & 48.0 & $62.0 * *$ \\
\hline \multicolumn{3}{|l|}{ Living status } \\
\hline On campus & 51.0 & $54.3 * *$ \\
\hline Off campus & 42.8 & $46.4 * *$ \\
\hline \multicolumn{3}{|l|}{ Transfer student } \\
\hline Yes & 48.1 & $54.8 * *$ \\
\hline No & 50.0 & $52.8 * *$ \\
\hline \multicolumn{3}{|l|}{ GPA } \\
\hline $0.0-1.0$ & 30.6 & 43.5 \\
\hline $1.1-2.0$ & 41.6 & 51.2 \\
\hline $2.1-3.0$ & 49.0 & 51.9 \\
\hline $3.1-4.0$ & 50.7 & $53.5 * *$ \\
\hline \multicolumn{3}{|l|}{ SAT/ACT Score } \\
\hline$<1200 /<16$ & 52.6 & 57.8 \\
\hline $1200-1400 / 17-19$ & 45.0 & 49.5 \\
\hline
\end{tabular}




\begin{tabular}{lcc}
\hline & \multicolumn{2}{c}{ Response rate (\%) } \\
\cline { 2 - 3 } & Generic greeting & Personalized greeting \\
\hline $1401-1570 / 20-22$ & 46.6 & 49.0 \\
$1571-1780 / 23-25$ & 58.8 & 62.1 \\
$>1780 />25$ & 50.0 & 51.0 \\
\hline
\end{tabular}

$* p<.05, * * p<.01$.

${ }^{\mathrm{a}}$ Excludes School D because it did not provide information on frame.

${ }^{b}$ Includes respondents who selected American Indian/Alaska Native, Other Pacific Islander, Other, or multiple races.

were greater than 0.05 , indicating good model fit ( $p=0.341$ for model 1 , and $p=0.297$ for model 2).

\section{Results}

\section{BIVARIATE ANALYSIS}

Table 2 presents the results of the bivariate analysis. As shown, the personalized greeting produced a modestly lower victimization rate ( 9.8 percent) compared to the generic greeting (10.6 percent); this difference was statistically significant. Further, the personalized greeting produced significantly lower victimization rates compared with the generic greeting for students at School B (11.4 percent vs. 13.2 percent), first-year students (9.7 percent vs. 12.4 percent), 18-year-olds (10.9 percent vs. 13.6 percent), and non-Hispanic whites (8.8 percent vs. 9.9 percent).

\section{MULTIVARIATE ANALYSIS}

To confirm the bivariate results for the hypothesis, a main-effects model was fit. Table 3 presents the predicted probabilities for the greeting type, and the student characteristics and the $p$-value for the adjusted Wald-F statistic for each characteristic. The model results indicate that, once controlling for student characteristics, the greeting type did not significantly influence how students reported sexual assault $(p=0.278)$.

To confirm the bivariate results for the research question, the interaction between greeting type and the student characteristics was included in the model. Table 4 presents the predicted probabilities for each of the student characteristic interactions by greeting type and the $p$-value for the adjusted Wald F. The model results indicate that after controlling for student characteristics, the greeting significantly impacted how students reported sexual assault across schools $(p=0.0401)$ and year of study $(p=0.0432)$. Within schools, 
Table 2. Victimization rates by greeting and student characteristics

\begin{tabular}{|c|c|c|}
\hline & \multicolumn{2}{|c|}{ Prevalence of sexual assault (\%) } \\
\hline & $\begin{array}{l}\text { Generic } \\
\text { greeting }\end{array}$ & $\begin{array}{l}\text { Personalized } \\
\text { greeting }\end{array}$ \\
\hline All students & 10.6 & $9.8^{*}$ \\
\hline \multicolumn{3}{|l|}{ School } \\
\hline A & 15.4 & 13.6 \\
\hline $\mathrm{B}$ & 13.2 & $11.4 *$ \\
\hline $\mathrm{C}$ & 5.0 & 5.9 \\
\hline $\mathrm{D}$ & 9.5 & 8.9 \\
\hline \multicolumn{3}{|l|}{ Gender identity } \\
\hline Male & 3.6 & 3.6 \\
\hline Female & 14.2 & 13.1 \\
\hline Transgender/Other & 13.3 & 20.0 \\
\hline \multicolumn{3}{|l|}{ Year of study } \\
\hline First & 12.4 & $9.7 * *$ \\
\hline Second & 11.2 & 11.4 \\
\hline Third & 9.6 & 9.9 \\
\hline Fourth or more & 9.2 & 8.4 \\
\hline \multicolumn{3}{|l|}{ Age } \\
\hline 18 & 13.6 & $10.9 *$ \\
\hline 19 & 12.7 & 11.5 \\
\hline 20 & 10.1 & 11.2 \\
\hline 21 & 11.6 & 10.2 \\
\hline 22 or older & 7.0 & 6.4 \\
\hline \multicolumn{3}{|l|}{ Race/Ethnicity } \\
\hline White, non-Hispanic & 9.9 & $8.8^{*}$ \\
\hline Black, non-Hispanic & 12.2 & 14.6 \\
\hline Hispanic & 11.7 & 12.0 \\
\hline Asian & 7.7 & 8.3 \\
\hline Other ${ }^{\mathrm{a}}$ & 13.2 & 13.0 \\
\hline \multicolumn{3}{|l|}{ Sexual orientation } \\
\hline Heterosexual & 9.7 & 9.0 \\
\hline Nonheterosexual & 15.9 & 14.8 \\
\hline
\end{tabular}

${ }^{*} p<.05, * * p<.01$.

${ }^{a}$ Includes respondents who selected American Indian/Alaska Native, Other Pacific Islander, Other, or multiple races.

only School C had a significantly different victimization rate across treatment groups $(p=0.0186)$, with the personalized greeting yielding a higher rate than the generic greeting (4.7 percent vs. 3.6 percent). Within year of study, no group had significantly different rates at the 0.05 level and only first-year students were significant at the 0.10 level $(p=0.0756)$. The Wald test was 
Table 3. Predicted probabilities for reporting victimization: main-effects model

\begin{tabular}{lcc}
\hline & $\begin{array}{c}\text { Predicted probability } \\
\text { of sexual assault }\end{array}$ & $\begin{array}{c}\text { Adjusted Wald-F } \\
p \text {-value }\end{array}$ \\
\cline { 2 - 3 } Student & $\%(S E)$ & 0.2777 \\
characteristics & & \\
\hline Greeting type & $8.0(0.3)$ & $<0.0001$ \\
Generic & $7.6(0.3)$ & \\
Personalized & & \\
School & $12.6(0.5)$ & $<0.0001$ \\
A & $9.7(0.4)$ & \\
B & $4.2(0.2)$ & \\
C & $7.4(0.4)$ & \\
D & $3.1(0.2)$ & \\
Gender identity & $12.4(0.3)$ & \\
Male & $11.6(3.5)$ & \\
Female & & \\
Transgender/Other & $8.2(0.4)$ & \\
Year of study & $8.5(0.4)$ & \\
First & $7.3(0.4)$ & \\
Second & $7.1(0.4)$ & \\
Third & & \\
Fourth or more & $8.0(0.3)$ & \\
Race/Ethnicity & $8.4(0.9)$ & \\
White, non-Hispanic & $8.7(0.6)$ & \\
Black, non-Hispanic & $4.5(0.4)$ & \\
Hispanic & $9.5(0.9)$ & \\
Asian & $7.5(0.2)$ & \\
Other & & \\
Sexual orientation & & \\
Heterosexual & & \\
Nonheterosexual & & \\
\hline
\end{tabular}

ancludes respondents who selected American Indian/Alaska Native, Other Pacific Islander, Other, or multiple races.

likely significant because the direction of change for first-year students was the opposite of the other three years of study.

\section{Discussion}

The bivariate analysis indicated that the personalized greeting suppressed sexual assault reporting; however, after controlling for student characteristics, the predicted probabilities of reporting victimization were statistically equivalent. Thus, any differences found in the bivariate analysis were likely 


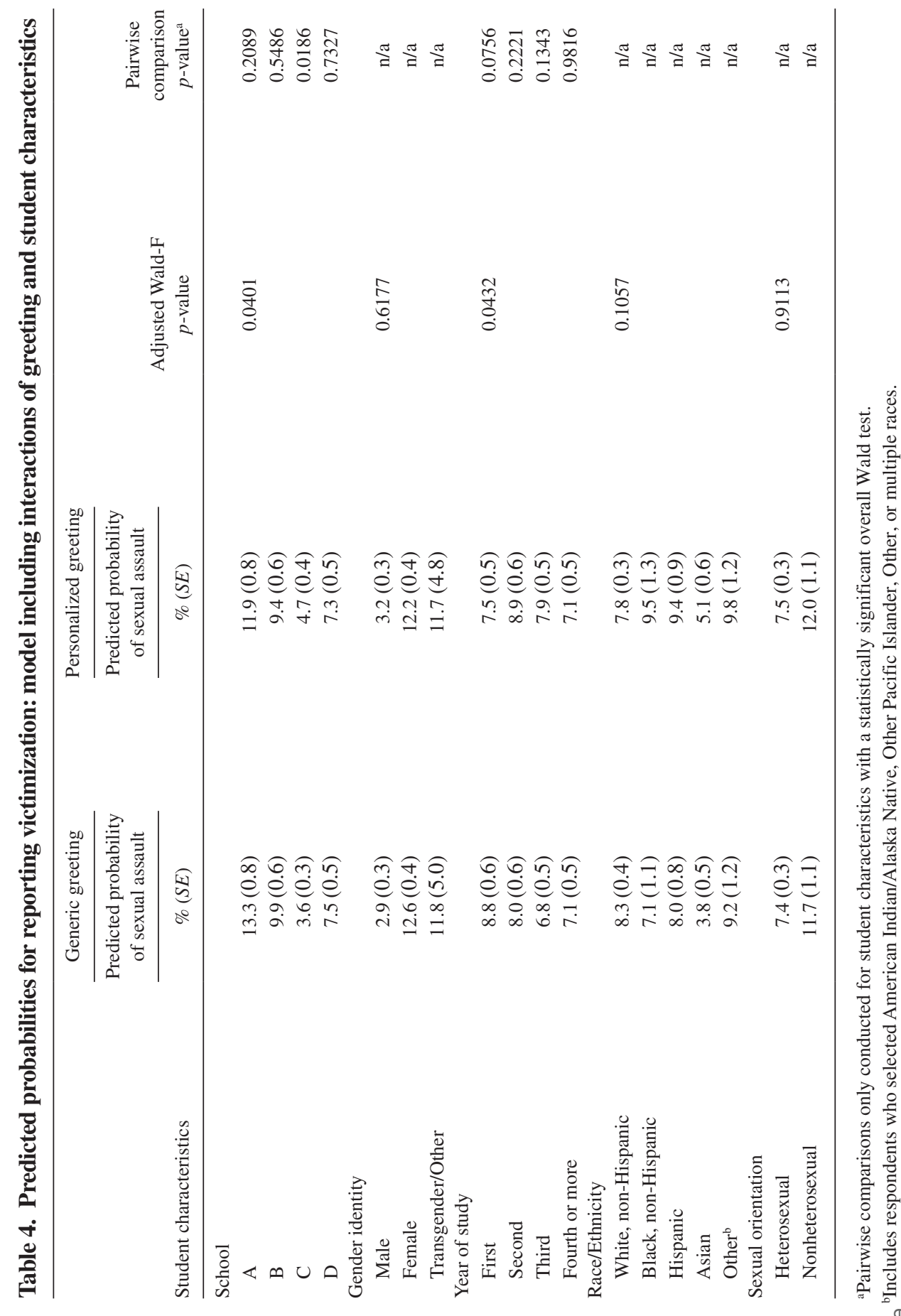


due to differences in the composition of respondents across the two greeting types, rather than differences due to the greeting itself. There is not statistical evidence to support the hypothesis that the personalized greeting would suppress sexual assault reporting. Namely, at the aggregate level, the personalized greeting increased response by 3.5 percentage points without impacting the reported sexual assault prevalence rate.

Further findings indicate that after controlling for student characteristics, victimization reporting differed by greeting only with respect to school attended and year of study. Race-for which non-Hispanic whites were significantly different in the bivariate analysis - was no longer significant after controlling for the other characteristics. For school attended, the statistical significance between greeting types was caused by School C (the only school with statistically different rates) having higher predicted prevalence rates when the personalized greeting was used, compared with the other three schools, where the personalized greeting led to lower prevalence rates. Other measures in the survey, such as students' perceptions of campus climate, could be examined to see whether School C's climate differs in a way that might explain why personalization uniquely impacted prevalence rates at this school. Unfortunately, those findings could be paired with previously published findings from the study to compromise the confidentiality of the schools' identities, so this possible explanation was not examined. ${ }^{5}$

Therefore, one note of caution on the results is that for some schools, greeting type may have unexpected impacts on reporting sexual assault. For studies making estimates at the primary sampling unit level, this caution may be important. For year of study, the statistical difference by greeting type was caused by second- through fourth-year students having higher reported prevalence rates when the personalized greeting was used, unlike first-year students, who had lower prevalence rates. Why personalization impacted students differently is unclear; further experiments to replicate and/or explain this finding are needed. Perhaps second- through fourth-year students are more trusting of their school's administration, more aware of how common sexual assault is, more aware of the importance of reporting victimization and the positive impact that can result, or have more established support systems and would be better equipped to handle a breach of confidentiality.

Consistent with prior research, the personalized greeting resulted in higher response rates than the generic greeting. Response rates were about 3.5 percentage points higher for the personalized greeting, which is a less pronounced impact than observed in prior research. This muted effect of personalization could be due to a couple factors. First, including school name in the generic greeting made it semi-personalized and was done deliberately to reap benefits

5. One of the agreements made between BJS and the participating schools was that the schools would not be identified. 
of personalization without introducing privacy concerns. The relatively small difference between the generic and personalized response rates suggests the semi-personalization was effective. However, this is purely speculative, as a completely impersonalized condition (e.g., "Dear Student") was not examined. Second, the response rates were relatively high already. Sample members may have been motivated to participate because of the survey's desirable incentives, support from trusted school administrators, encouragement from participating friends, and recent widespread media attention to the topic. Some of these factors also may have impacted victimization reporting. Thus, the finding that the personalized greeting had little impact on victimization reporting may not hold across all surveys, particularly when sample members lack a pre-established, trusting relationship with the survey sponsor.

A limitation of this research is that the sample is not nationally representative. The selected schools could differ from a nationally representative sample of schools on factors that contribute to reporting victimization, such as campus climate. Future research should examine the extent to which these findings differ across a larger, randomly selected sample of schools. This is especially important given the unexpected finding that School C students, who received the personalized greeting, were more likely to report victimization. Further research also is needed with the general population, to which findings about students are not generalizable. Personalization may impact other segments of the population differently, based on characteristics such as age, education, or digital literacy.

Overall, the findings did not provide strong enough evidence to discourage the use of a personalized greeting in an extremely sensitive survey. The findings suggest that the personalized greeting increased response rates without impacting overall rates of reported sexual assault victimization, except for School C and first-year students. At School C, the personalized greeting produced a higher victimization rate. This suggests that personalization produced a more accurate estimate and is consistent with the recommendation to use a personalized greeting, even on sensitive surveys. However, more research is needed to explore reporting differences among first-year students. Other areas for future research include (1) examining the impact of personalization on sensitive surveys when sample members are less familiar with or trusting of the survey sponsor; and (2) examining the impact on the general population, especially across the subgroups noted above that are likely to be differentially affected. These investigations would be imperative in determining how best to personalize contacts in sensitive surveys.

\section{References}

American Association for Public Opinion Research. 2015. "Standard Definitions: Final Dispositions of Case Codes and Outcome Rates for Surveys." American Association for Public Opinion Research (AAPOR) 8 th ed. 
Bradburn, Norman M., Seymour Sudman, Ed Blair, and Carol Stocking. 1978. "Question Threat and Response Bias." Public Opinion Quarterly 42:221-34.

Cook, Coleen, Fred Heath, and Russell L. Thompson. 2000. "A Meta-Analysis of Response Rates in Web- or Internet-Based Surveys." Educational and Psychological Measurement 60:821-36.

Edwards, Philip James, Ian Roberts, Mike J. Clarke, Carolyn DiGuiseppi, Reinhard Wentz, Irene Kwan, Rachel Cooper, Lambert M. Felix, and Sarah Pratap. 2009. "Methods to Increase Response to Postal and Electronic Questionnaires." Cochrane Database of Systematic Reviews 8(3):1-527. doi:10.1002/14651858.MR000008.pub4

Heerwegh, Dirk. 2005. "Effects of Personal Salutations in E-Mail Invitations to Participate in a Web Survey." Public Opinion Quarterly 69:588-98.

Heerwegh, Dirk, and Geert Loosveldt. 2006. "Personalizing E-Mail Contacts: Its Influence on Web Survey Response Rate and Social Desirability Response Bias." International Journal of Public Opinion Research 19:258-67.

Heerwegh, Dirk, Tim Vanhove, Koen Matthijs, and Geert Loosveldt. 2005. "The Effect of Personalization on Response Rates and Data Quality in Web Surveys." International Journal of Social Research Methodology 8:85-99.

Joinson, Adam N., and Ulf-Dietrich Reips. 2007. "Personalized Salutation, Power of Send and Response Rates to Web-Based Surveys." Computers in Human Behavior 23:1372-83.

Joinson, Adam N., Alan Woodley, and Ulf-Dietrich Reips. 2007. "Personalization, Authentication and Self-Disclosure in Self-Administered Internet Surveys." Computers in Human Behavior 23:275-85.

Krebs, Christopher, Christine Lindquist, Marcus Berzofsky, Bonnie Shook-Sa, Kimberly Peterson, Michael Planty, Lynn Langton, and Jessica Stroop. 2016. "Campus Climate Survey Validation Study Final Technical Report." Available at http://www.bjs.gov/content/pub/pdf/ccsvsftr.pdf.

Muñoz-Leiva, Francisco, Juan Sánchez-Fernández, Francisco Montoro-Ríos, and José Ángel Ilbáñez-Zapata. 2010. "Improving the Response Rate and Quality in Web-Based Surveys through the Personalization and Frequency of Reminder Mailings." Quality \& Quantity 44:1037-52.

Pearson, Jerold, and Roger A. Levine. 2003. "Salutations and Response Rates to Online Surveys." In Association for Survey Computing Fourth International Conference on the Impact of Technology on the Survey Process, September 19, University of Warwick.

Porter, Stephen R., and Michael E. Whitcomb. 2003. "The Impact of Contact Type on Web Survey Response Rates." Public Opinion Quarterly 67:579-88.

Sauermann, Henry, and Michael Roach. 2013. "Increasing Web Survey Response Rates in Innovation Research: An Experimental Study of Static and Dynamic Contact Design Features." Research Policy 42:273-86.

Tourangeau, Roger, Lance J. Rips, and Kenneth Rasinski. 2000. The Psychology of Survey Response. Cambridge: Cambridge University Press.

Tourangeau, Roger, and Ting Yan. 2007. "Sensitive Questions in Surveys." Psychological Bulletin 133:859-83. 